\title{
Advanced numerical modelling of friction stir welded low alloy steel
}

Bilal Ahmad*, Alexander Galloway, Athanasios Toumpis

Department of Mechanical \& Aerospace Engineering, University of Strathclyde, James Weir Building, 75 Montrose Street, Glasgow G1 1XJ, United Kingdom

* Corresponding author. Tel.: +44 (0) 141574 5076,

e-mail address: bilal.ahmad@strath.ac.uk 


\begin{abstract}
The development of advanced joining processes such as friction stir welding (FSW) is necessary to maintain manufacturing competitiveness in any industrial nation. Substantial research that has been carried out on FSW of aluminium alloys has demonstrated considerable benefits; this has led to greater interest in FSW of steel and other high melting temperature alloys. In this context, numerical modelling can provide costeffective development of steel FSW. Due to the limitations associated with the Johnson Cook model when employed in high melting temperature metals, a three-dimensional thermo-mechanical simulation of FSW featuring low alloy steel with previously generated experimental temperature dependant properties has been successfully solved in Abaqus/Explicit. Unlike any previous research in which either the workpiece is assumed as a high viscous body or the tool is modelled as a moving heating source, the Coupled Eulerian Lagrangian approach has been innovatively applied to model the FSW process on steel. All stages of FSW (plunge, dwell and traverse) have been modelled for slow and fast process parameters and their results compared with previous experimental work on the same grade of steel. In each model, the weld shape and weld surface flash were found to be in exceptionally close alignment with previous experimental results.
\end{abstract}

Keywords: friction stir welding; finite element modelling; coupled Eulerian Lagrangian; DH36; flash formation; temperature distribution

\title{
1. Introduction
}

Friction stir welding (FSW) is considered to be a remarkable advancement in material joining in the previous years [1]. It is a solid state joining process that plasticises the material during welding. Heat is generated by the plastic deformation and the frictional contact between the tool and the workpiece, which in turns, softens the material around the tool [2]. Several studies show that significant reduction in porosity [3], cracking [1], distortion and reinforcement dissolution [4] can be achieved with the FSW process. It provides exceptional surface finish, low maintenance and energy costs along with enhanced fatigue strength of welded components compared to other welding techniques like electric or gas arc welding [5].

To date, FSW has been successfully applied for the welding of aluminium and other low 
melting point alloys [3]. There has been recent research carried out on FSW of steel and high strength alloys [6,7]. The factors affecting the quality of friction stir welds are normally rotational and traverse speed of the tool, plunging force of the tool on the workpiece, and the angle of the contact between the tool and workpiece [8]. FSW process parameters such as tool rotational and traverse speed greatly influence the heat input, cooling rate and the quality of the welds produced [9]. The main issues behind the particularly limited application of FSW of steel are the short life and high cost of FSW tools [10]. The design of the FSW tool is primarily influenced by material selection, geometry and production cost. The tool technology for welding steel is comparatively underdeveloped and more research needs to be conducted to ensure that the whole welding process becomes entirely independent from the tool's life [11]. Polycrystalline boron nitride ( $\mathrm{pcBN}$ ) is mainly being used as the tool material for steel welding with the maximum welding length as $40 \mathrm{~m}$ per tool [12]. The pcBN material is considered expensive and has also been shown to exhibit cracks and significant wear, both of which are detrimental to the weld characteristics [3].

Numerical simulation is a cost-effective means of investigating and predicting different physical phenomena during FSW [13]. From a modelling perspective, it is important to capture the numerical results of the process as close to the experimentally generated data as possible such as the temperature gradient, surface features and material flow in the workpiece. This allows an evaluation of the diverse process parameters, for instance tool geometry and process parameters [8].

Numerous researchers [13-21] have considered various types of FSW numerical models. Simulation techniques in the literature mainly assume either the rotating tool as a moving heating source or the workpiece as a viscous fluid body. Camilleri et al. [14] developed a FSW numerical model for DH36 workpiece by replacing the solid tool with a heat source. They calculated thermal stresses in the workpiece and found that fast welding conditions result in lower peak temperatures [14]. A computational fluid dynamic (CFD) model was developed by Al-Moussawi et al. [18], where the material flow in the workpiece was analysed by considering the solid workpiece as a highly viscous fluid body. It was concluded that for the slow welding conditions, the maximum temperature lied under the tool shoulder whereas for fast welding conditions, it existed in the shear layer just out the tool shoulder periphery [18]. In addition, the minimum temperature was located in the probe end, and the cooling rate was increased by 
increasing the traversing speed [18]. To make a fully developed model with realistic boundary conditions, , the Arbitrary Lagrangian Eulerian (ALE) approach has been used, in which the viscoplastic flow and the heat transfer effects are modelled simultaneously in the system to predict temperature and residual stress distributions [19]. This has only been used for modelling aluminium and low melting temperature alloys. Various other researchers simplify the numerical model to such an extent that the numerical proficiency of the model leads to deficient results [22]. Many thermomechanically coupled features such as temperature dependent material deformation, heat generation due to the frictional contact and potential defects in the workpiece are often overlooked by such numerical approaches.

When it comes to solving large displacement problems, a relatively new modelling approach named Coupled Eulerian Lagrangian (CEL) has demonstrated very promising results as compared to other simulation techniques [23]. As its name suggests, it principally includes two domains, Eulerian and Lagrangian. The Eulerian domain is calculated by spatial time derivatives while material time derivatives are used for the Lagrangian domain [24]. Both sets of equations are related together and are then calculated simultaneously. Stiffer bodies in the model are considered as Lagrangian elements while the bodies undertaking large deformations are discretised with Eulerian elements [24]. Initially, a part of the Eulerian domain is typically filled with material properties, while the rest of it is left empty and often regarded as a section referred to as a "void" [23]. This allows elements of the material to be displaced from their initial position into the "void" section if required.

Recently, the Coupled Eulerian Lagrangian (CEL) approach has been used to successfully model FSW of aluminium with minimum assumptions (solid tool instead of virtual heat source and solid workpiece instead of viscous fluid body) in order to visualise more realistic results $[25,26]$. In both ALE and CEL approaches, Johnson Cook's (JC) material properties of aluminium have been used in the literature to model the FSW process. Johnson Cook's model calculates several constants for monitoring the material's behaviour. When using the JC model, the welding process is initiated after the material temperature is raised to a theoretically calculated JC melting temperature that is different from the actual melting temperature of the material. For the case of aluminium, the JC model yields approximately realistic results as the JC melting temperature for aluminium lies in the range of $75-85 \%$ of its actual melting temperature 
[27]. This cannot be achieved in steel as the JC model gives an inaccurate melting temperature value $\left(\sim 1300^{\circ} \mathrm{C}-1400^{\circ} \mathrm{C}\right)$ which is unrealistic since $\mathrm{FSW}$ of steel typically occurs below $1000^{\circ} \mathrm{C}[28]$.

The current research work advances the scientific understanding on the FSW of structural steel by developing a thermo-mechanical model with three major novelties; experimentally generated boundary conditions, actual high temperature dependant material properties and simulation of tool/workpiece as solid bodies. These three aspects have not been previously implemented for the numerical simulation of steel FSW and have allowed the present model to produce more realistic results on this solid state joining process. Both structural and thermal conditions have been solved in parallel so that the effect of one parameter on the other can be studied. Therefore, a better analysis is achieved by the examination of the tool's impact on the whole process. Numerical results have been validated by extensive experimental data generated in a previous comprehensive research work [6] on the same grade of steel and process conditions.

\section{Methodology}

\subsection{Model description}

A three dimensional finite element model has been developed and solved using Abaqus/Explicit. In explicit dynamics, any force or displacement occurring in a system can be calculated by the equation of motion (equation 1 ).

$P=M \ddot{u}+C \dot{u}+K u$

Where "P" denotes the total force or displacement and the other three terms on the right side of the equation refer to an inertial factor for any movement, sum of all energies being damped and the total stiffness of the body, respectively. The expression " $u$ " symbolises the displacement in the model so notations " $\dot{\mathrm{u}}$ " and "ü" represents velocity and acceleration due to the force acting in that system. " $\mathrm{M}$ ", " $\mathrm{C}$ " and " $\mathrm{K}$ " signifies as the mass, damping coefficient and stiffness coefficient of the body, respectively.

A fully coupled thermal-displacement approach was applied to calculate the thermal and structural response of the model simultaneously. The heat transfer was achieved through 
integrating equation 2 and applying the explicit forward difference time integration rule [29]:

$\theta_{(\mathrm{i}+1)}^{\mathrm{N}}=\theta_{(\mathrm{i})}^{\mathrm{N}}+\Delta \mathrm{t}_{(\mathrm{i}+1)} \dot{\theta}_{(\mathrm{i})}^{\mathrm{N}}$

Where $\theta^{\mathrm{N}}$ refers to the temperature at a specific node $\mathrm{N}$ with " $\mathrm{i}$ " number of increments in the explicit dynamic step, and $\dot{\theta}_{(\mathrm{i})}^{\mathrm{N}}$ denotes the current temperature value as calculated from the previous increment. For the beginning of the increment, its value is computed by:

$\dot{\theta}_{(\mathrm{i})}^{\mathrm{N}}=\left(\mathrm{C}^{\mathrm{NJ}}\right)^{-1}\left(\mathrm{P}_{(\mathrm{i})}^{\mathrm{J}}-\mathrm{F}_{(\mathrm{i})}^{\mathrm{J}}\right)$

Where, $\mathrm{C}^{\mathrm{NJ}}$ is the lumped capacitance matrix, $\mathrm{P}^{\mathrm{J}}$ is the applied nodal source and $\mathrm{F}^{\mathrm{J}}$ is the internal flux vector.

The structural solution response was obtained by integrating equation 1 with the application of the explicit central difference integration rule [30]. A lumped mass matrix is also applied together with the explicit integration rule in equation 4:

$\mathrm{N}_{\left(\mathrm{i}+\frac{1}{2}\right)}=\dot{\mathrm{u}}_{\left(\mathrm{i}-\frac{1}{2}\right)}^{\mathrm{N}}+\frac{\Delta \mathrm{t}_{(\mathrm{i}+1)}+\Delta \mathrm{t}_{(\mathrm{i})}}{2} \ddot{\mathrm{u}}_{(\mathrm{i})}^{\mathrm{N}}$

$\mathrm{u}_{(\mathrm{i}+1)}^{\mathrm{N}}=\mathrm{u}_{(\mathrm{i})}^{\mathrm{N}}+\Delta \mathrm{t}_{(\mathrm{i}+1)} \dot{\mathrm{u}}_{\left(\mathrm{i}+\frac{1}{2}\right)}^{\mathrm{N}}$

Here, $\mathrm{u}^{\mathrm{N}}$ represents either a displacement or rotational component with "i" number of increments in the explicit dynamic step. "N" as specified before is a node under consideration. The kinetic state uses known values of $\dot{\mathrm{u}}_{\left(\mathrm{i}-\frac{1}{2}\right)}^{\mathrm{N}}$ and $\ddot{\mathrm{u}}_{(\mathrm{i})}^{\mathrm{N}}$ from the previous increment.

The CEL approach has been applied to predict the temperature distribution in the workpiece and visualisation of the flash produced on the surface during FSW. The workpiece was modelled as an Eulerian body while the tool was modelled as a Lagrangian body (in Fig. 1). The tool Lagrangian domain was meshed with 6072 thermally coupled 8-node brick elements C3DRT while the workpiece Eulerian domain was meshed with 25192 thermally coupled 8-node Eulerian elements EC3D8RT. The Eulerian body included two regions, full and void. The outer region ("void") contained 
no initial DH36 material properties while the inner region ("full") was assigned with the DH36 workpiece material properties.

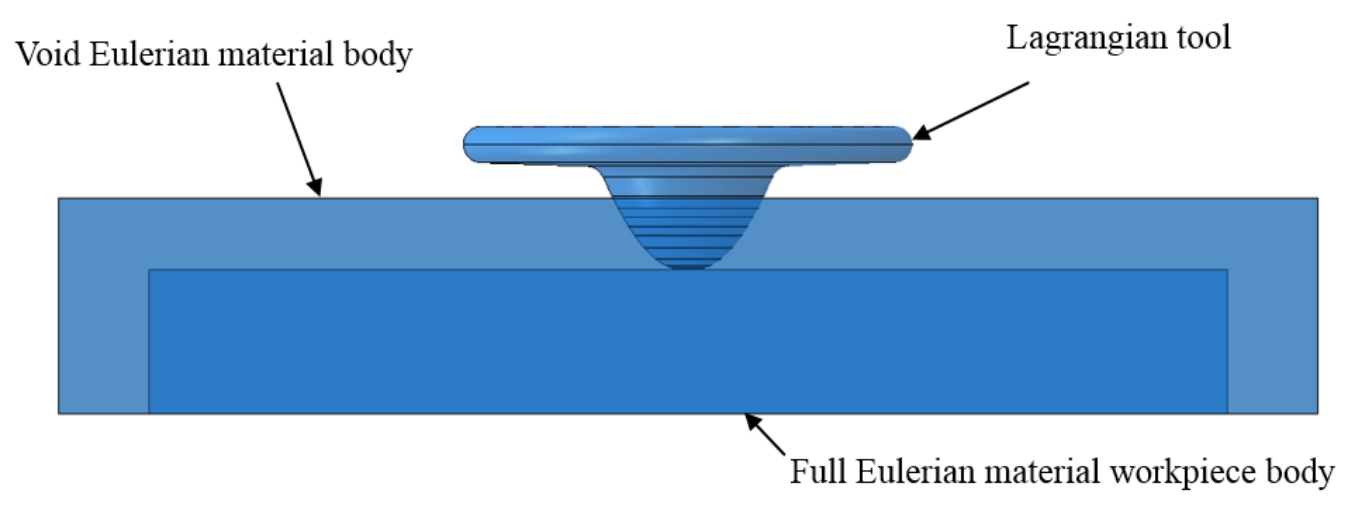

Fig. 1. Illustration of the CEL approach with material assignment.

The experimental results have been produced by using a pcBN FSW tool and $6 \mathrm{~mm}$ thick DH36 workpiece [6]. A number of the macrographs from these experiments have been published in earlier work [6] and are also used herein.

\subsection{Model geometry}

The geometrical dimensions of the FSW tool for steel have been taken from the relevant technical literature [6,31]. The tool's dimensions are shown in Fig. 2. The tool has been dismantled to examine the geometry and material of its components. It is made up of three material parts, i.e. pcBN probe and shoulder, tungsten carbide shank and two steel collars that hold the shank and shoulder to avoid any horizontal or vertical movement. 


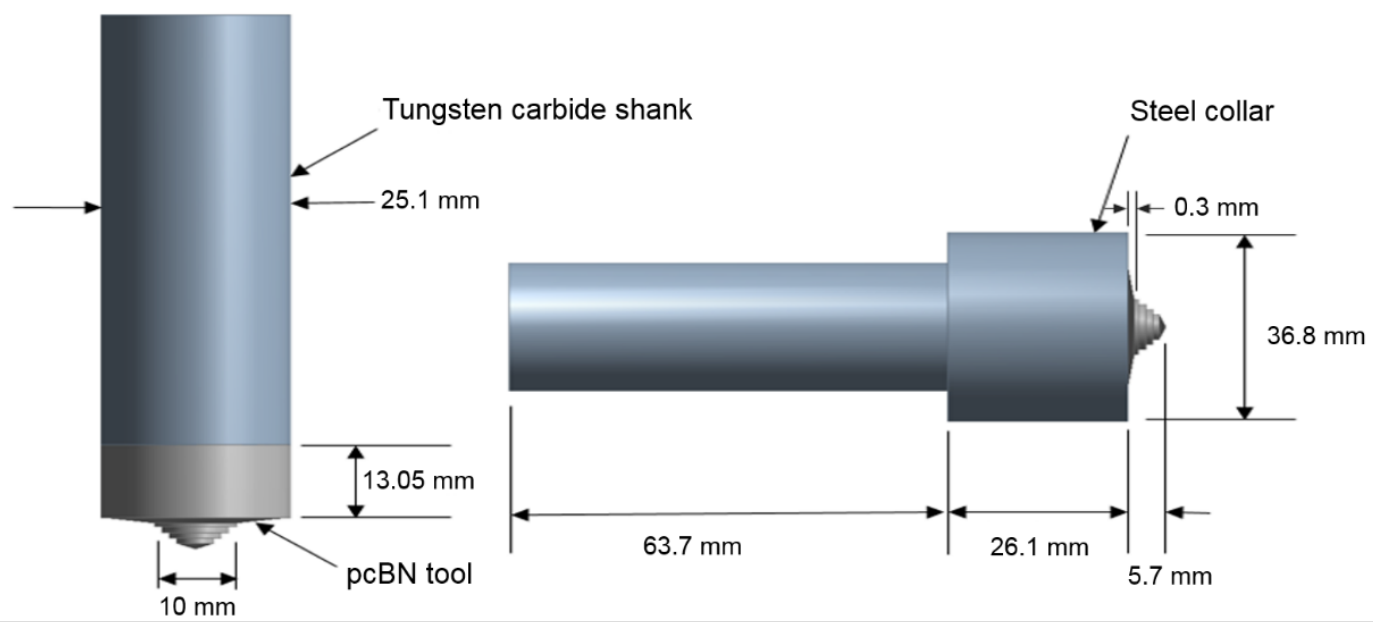

Fig. 2. FSW tool geometrical dimensions [6,31].

To reduce the computational time, the tool was simplified by ignoring the spiral threads on the shoulder and probe while keeping the overall dimensions same, as shown in Fig. 3. The tool consisted of shoulder and probe, and was treated as a rigid body. The shoulder diameter was kept as $25 \mathrm{~mm}$ while the probe height and diameter were $5.7 \mathrm{~mm}$ and $10 \mathrm{~mm}$ respectively.

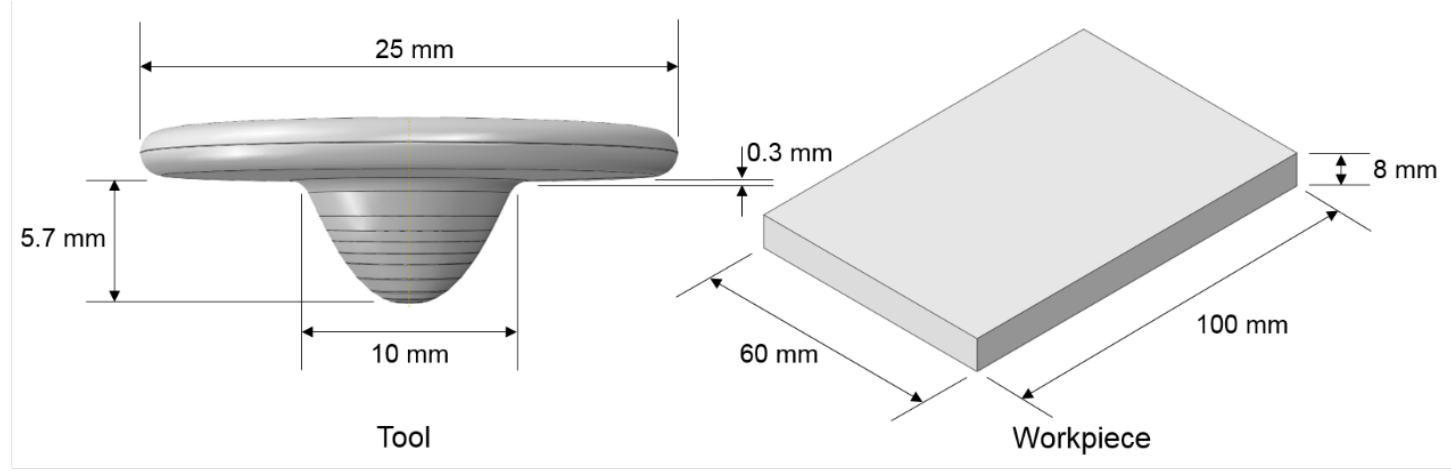

Fig. 3. Simplified tool and workpiece geometrical dimensions.

The workpiece modelled in this study is an $8 \mathrm{~mm}$ thick DH36 plate with $100 \mathrm{~mm}$ length and $60 \mathrm{~mm}$ width whereas the length and width of the welded workpiece from the experiments, with which the numerical results are compared, were $2000 \mathrm{~mm}$ and 400 $\mathrm{mm}$ respectively [6]. The chemical composition of DH36 examined previously [6] has been presented in Table 1 . 
Table 1. Percentage chemical composition of DH36 with respect to weight.

\begin{tabular}{|c|c|c|c|c|c|c|c|}
\hline $\mathrm{C}$ & $\mathrm{Mn}$ & $\mathrm{Si}$ & $\mathrm{P}$ & $\mathrm{S}$ & $\mathrm{Al}$ & $\mathrm{Nb}$ & $\mathrm{N}$ \\
\hline 0.11 & 1.48 & 0.37 & 0.014 & 0.004 & 0.02 & 0.02 & 0.002 \\
\hline
\end{tabular}

\subsection{Material properties}

Temperature dependent material properties such as coefficient of thermal expansion, thermal conductivity and specific heat were used to acquire realistic results. The specific heat and thermal conductivity graphs are shown in Fig. 4. Mechanical properties of DH36 were included from the work carried out by $[7,11,28]$. Density was kept constant as $7830 \mathrm{~kg} \cdot \mathrm{m}^{-3}$ since changing temperature has a negligible effect on it.

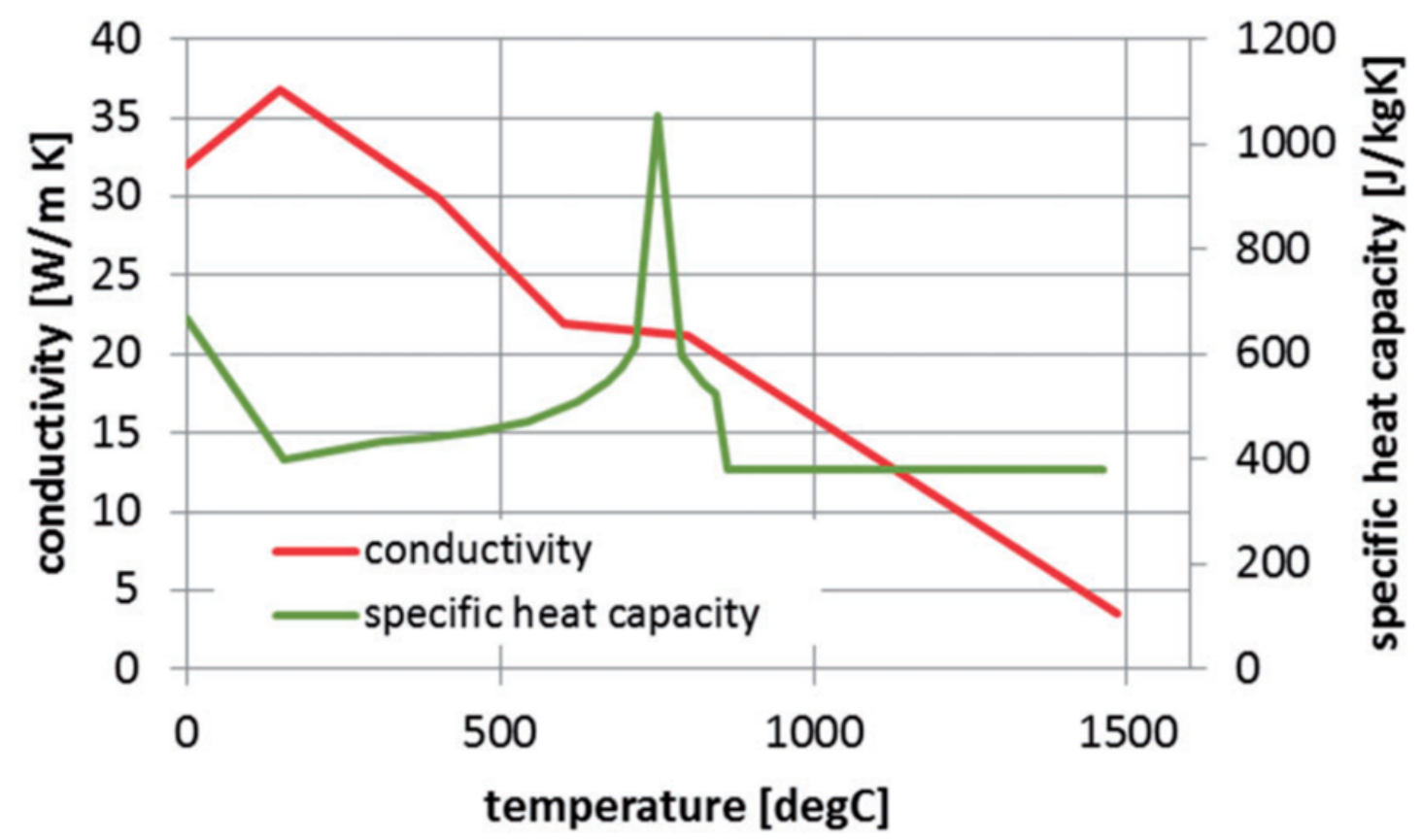

Fig. 4. Temperature dependent thermal conductivity and specific heat capacity of DH36 steel [28].

To observe the viscoplastic behaviour of DH36, thermoplastic properties such as yield stress, strain and strain rates were fed into the model. The DH36 steel's yield stress $\bar{\sigma}$ is dependent on work hardening which has been represented as a function of equivalent plastic strain $\bar{\varepsilon}^{\mathrm{pl}}$, inelastic strain rate $\dot{\varepsilon}^{\mathrm{pl}}$ and temperature $\theta$ for this specific model as shown in equation 6 [32]. 
$\bar{\sigma}=\bar{\sigma}\left(\bar{\varepsilon}^{\mathrm{pl}}, \dot{\varepsilon}^{\mathrm{pl}}, \theta\right)$

The strain rate and temperature dependent flow stress of the workpiece material was obtained from earlier work [7], in which 58 uniaxial compression tests were performed on a Gleeble 3800 thermo-mechanical testing system. Stresses and strains were experimentally measured with a wide range of strain rates from $10^{-2} \mathrm{~s}^{-1}$ to $100 \mathrm{~s}^{-1}$ and temperature change from $700^{\circ} \mathrm{C}$ to $1100^{\circ} \mathrm{C}$. It was reported that material flow below $700^{\circ} \mathrm{C}$ and with low strain rate was found to be essentially insignificant [7]. A typical true stress versus strain curves is shown in Fig. 5 as a function of strain rates of $0.1,1$, 10 and $50 \mathrm{~s}^{-1}$.

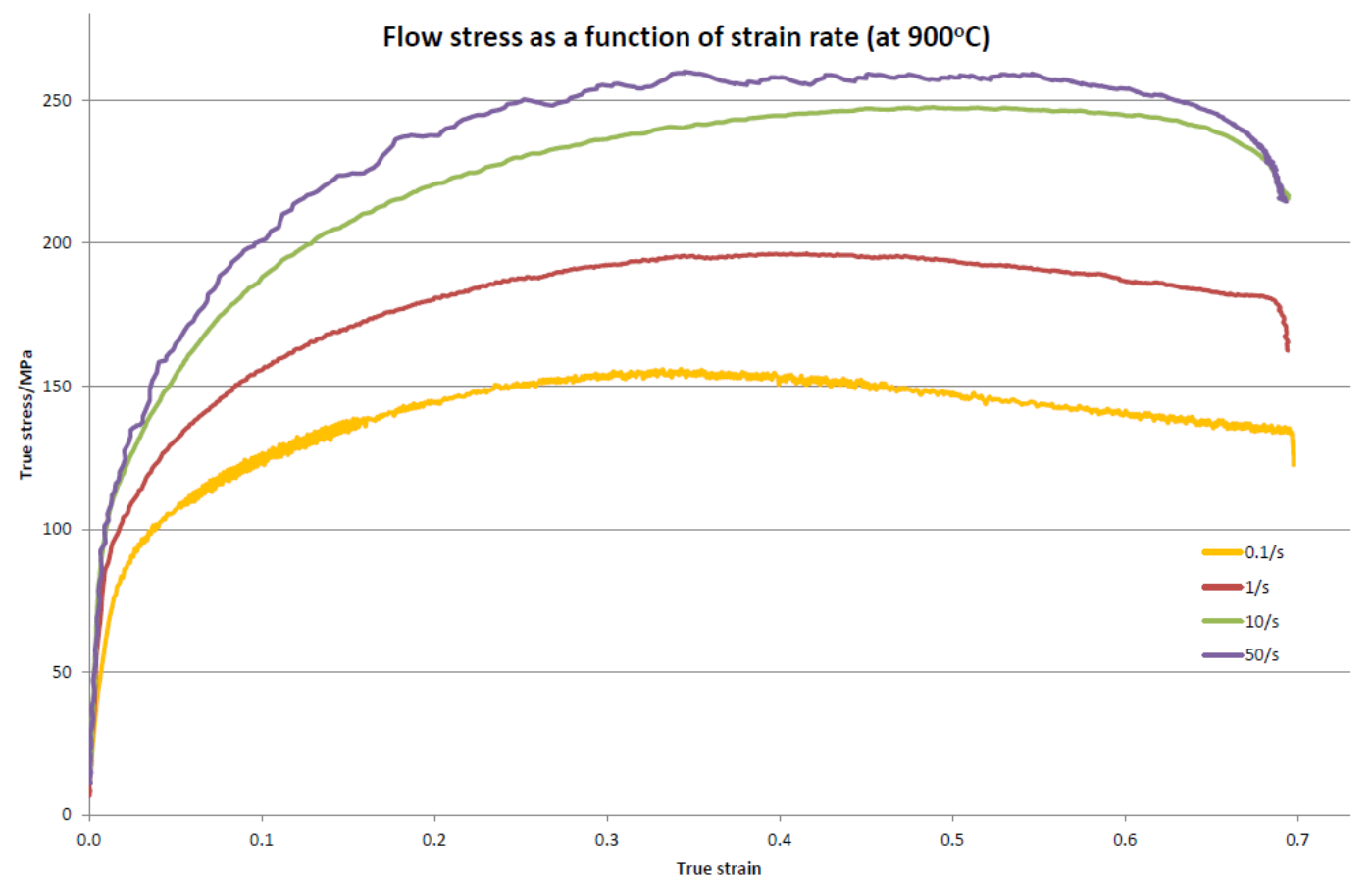

Fig. 5. True stress vs strain curve at $900^{\circ} \mathrm{C}$ [7].

Material's thermal conductivity, specific heat capacity and density were used for the pcBN tool and are shown in Table 2 [31]. 
Table 2. Material properties of the pcBN tool.

\begin{tabular}{|c|c|c|c|c|}
\hline $\begin{array}{c}\text { Thermal } \\
\text { conductivity }\end{array}$ & $\begin{array}{c}\text { Coefficient of } \\
\text { thermal } \\
\text { expansion }\end{array}$ & Density & Specific heat & $\begin{array}{c}\text { Young's } \\
\text { modulus }\end{array}$ \\
\hline $\mathrm{W} /(\mathrm{m} . \mathrm{K})$ & $10 \mathrm{E}-6 /{ }^{\circ} \mathrm{C}$ & $\mathrm{kg} \cdot \mathrm{m}^{3}$ & $\mathrm{~J} /(\mathrm{kg} \cdot \mathrm{K})$ & $\mathrm{N} / \mathrm{m}^{2}$ \\
\hline 150 & 4.7 & 4370 & 750 & $7.50 \mathrm{E}+11$ \\
\hline
\end{tabular}

\subsection{Boundary conditions}

Numerous process parameters of FSW were modelled; however, this study will discuss two diverse but indicative sets of process parameters. Table 3 represents different properties for each stage of the model. The model simulation included three stages: plunge, dwell and traverse.

Table 3. Process parameter specifications for models used in the study.

\begin{tabular}{|c|c|c|c|c|c|}
\hline \multirow{2}{*}{$\begin{array}{c}\text { Model } \\
\text { name }\end{array}$} & \multicolumn{2}{|c|}{ Plunge } & Dwell & \multicolumn{2}{c|}{ Traverse } \\
\hline \multirow{2}{*}{} & $\begin{array}{c}\text { Rotational } \\
\text { speed } \\
(\mathrm{rpm})\end{array}$ & $\begin{array}{c}\text { Feed rate in } \\
\text { downward } \\
\text { direction } \\
(\mathrm{mm} / \mathrm{min})\end{array}$ & $\begin{array}{c}\text { Rotational } \\
\text { speed } \\
(\mathrm{rpm})\end{array}$ & $\begin{array}{c}\text { Rotational } \\
\text { speed (rpm) }\end{array}$ & $\begin{array}{c}\text { Traverse } \\
\text { speed } \\
(\mathrm{mm} / \mathrm{min})\end{array}$ \\
\hline Slow Weld & 700 & 100 & 400 & 200 & 120 \\
\hline Fast Weld & 800 & 100 & 700 & 700 & 500 \\
\hline
\end{tabular}

The position control method has been applied in the current model to achieve an accurate tool probe depth, as it has been applied in a previous experimental work [6]. When the tool reached its maximum depth, it was maintained as rotating at the required rotational speed for 4 seconds to generate enough heat. Once the surrounding material was softened enough, the tool was traversed, thereby welding the workpiece with the provided traverse and rotational speed.

The coefficient of friction is a significant component in calculating the heat generation 
between two surfaces. Different researchers have estimated different values for different material interactions under specific conditions [33,34]. Nandan et al. [33] computed the friction coefficient by considering the relative velocity between rotating tool and workpiece and used a value of 0.4. Furthermore, Ambroziak et al. [34] determined the friction coefficient " $\mu$ " for steel S235 from equation 7:

$\mu=\frac{\mathrm{M}_{\mathrm{t}}}{\mathrm{r} \cdot \mathrm{P}_{\mathrm{t}}}$

Where $M_{t}$ refers to the friction torque in $\mathrm{Nm}, \mathrm{P}_{t}$ is the pressure force in $\mathrm{N}$ and $\mathrm{r}$ is the radius of the cylindrical welded specimen, considered as $8 \mathrm{~mm}$ in the study [34]. It was concluded that the friction coefficient was maximised in the low temperature range and was stabilised at 0.3 after reaching above $400^{\circ} \mathrm{C}$. The value of friction coefficient slightly decreased with increasing temperature [34]. Consequently, a constant friction coefficient value of 0.3 has been used in this study for both weld models.

Structural and thermal boundary conditions have been applied on the model. The workpiece was fully constrained from the bottom surface for the entire process.

The conductive heat transfer between the contact surfaces is assumed to be defined by:

$\mathrm{q}=\mathrm{h}\left(\theta_{\mathrm{A}}-\theta_{\mathrm{B}}\right)+\left(\varepsilon \alpha\left(\theta_{\mathrm{A}}{ }^{4}-{\theta_{\mathrm{B}}}^{4}\right)\right)$

Where $\mathrm{q}$ is the heat flux per unit area in $\mathrm{W} . \mathrm{m}^{-2}, \mathrm{~h}$ is the convective coefficient in W. $\mathrm{m}^{-2} . \mathrm{K}, \varepsilon$ is the emissivity coefficient, $\alpha$ is the Stefan-Boltzmann Constant $(5.6703 \mathrm{x}$ $10^{-8} \mathrm{~W} \cdot \mathrm{m}^{-2} \cdot \mathrm{K}^{-4}$ ) and $\theta$ is the temperature value from point $\mathrm{A}$ on one surface to point $\mathrm{B}$ on the other. Radiative heat transfer has been compensated by increasing the conductivity on the workpiece surfaces to avoid complexities in the model. Therefore, the top and side surfaces of the workpiece were assigned an increased convective film coefficient of $10 \mathrm{~W} \cdot \mathrm{m}^{-2} \cdot \mathrm{K}^{-1}$. Al-Moussawi et al. [18] used a computational fluid dynamics (CFD) model to represent material flow in DH36 steel. They suggested a convective film coefficient value of $2000\left(\mathrm{~W} \cdot \mathrm{m}^{-2} \cdot \mathrm{K}^{-1}\right)$ on the bottom surface of the workpiece to achieve realistic results. Hence, the same value was applied on the bottom surface of the workpiece in the present study to represent the influence of the backing plate. The sink temperature was provided as $25^{\circ} \mathrm{C}$. Gap conductance was applied to minimise mesh irregularity effects on the contact surfaces between the tool and the 
workpiece.

For the thermo-mechanical coupled surface interactions, the frictional energy dissipation rate in the model is assumed to be [35]:

$\mathrm{P}_{\mathrm{fr}}=\tau \cdot \dot{\gamma}$

Where $\tau$ represents the frictional stress and $\dot{\gamma}$ is the slip rate between two surfaces. The total amount the heat energy released on each surface is given by

$\mathrm{q}_{\mathrm{A}}=\mathrm{f \eta} \mathrm{P}_{\mathrm{fr}}$

$\mathrm{q}_{\mathrm{B}}=(1-\mathrm{f}) \eta \mathrm{P}_{\mathrm{fr}}$

Where $\eta$ is the fraction of dissipated energy converted into heat, $f$ is the amount of heat distributed into the slave surface of the contact pair which is the workpiece for this model and $\mathrm{q}_{\mathrm{A}}$ represents the heat flux into the workpiece, whilst $\mathrm{q}_{\mathrm{B}}$ denotes the heat flux into the tool. All energy generated by friction was converted into heat while $90 \%$ of the converted heat was assumed to be transferred into the workpiece [25].

\section{Results and Discussion}

Although a wide variety of models has been assessed, two characteristic models are discussed in this study (as classified in Table 3) for conciseness. To compare the results, the remaining features such as tool and workpiece material and geometries, frictional contact, heat transfer coefficient, etc. are kept identical for both models. Temperature distribution, plastic strain, flash generation and potential flaws have been calculated for the workpiece.

\subsection{Plunge stage}

Fig. 6 displays the temperature contours in the isometric view and cross sectional cuts of the slow and fast weld models for the plunge stage. Since the feed rate in the downward direction has been set as constant $(100 \mathrm{~mm} / \mathrm{min})$ for both models, the comparison of results in the plunge stage is solely based on the rotational speed of the tool. The temperature in the plunge stage for the fast weld model is slightly higher than that of the slow weld one as shown in the Fig. 6 . This is because of the high rotational 
speed in the fast weld than the slow weld model. Welding speed is not expected to affect the plunge stage. The thermo-mechanically affected zone (TMAZ) was identified as the region with maximum equivalent plastic strain (mainly near the tool and workpiece interface shown in Fig. 7), as illustrated in previous research [7]. For the slow weld model, the thermo-mechanically affected zone (TMAZ) lies above $770^{\circ} \mathrm{C}$ and the heat affected zone (HAZ) is in the temperature range of $370^{\circ} \mathrm{C}$ to $750^{\circ} \mathrm{C}$, whereas for the fast weld model, the maximum temperature in the TMAZ is $889^{\circ} \mathrm{C}$ and the $\mathrm{HAZ}$ is between $330^{\circ} \mathrm{C}$ to $889^{\circ} \mathrm{C}$. Note that cross sectional views in Fig. 6 to 11, i.e. those that present numerical and/or experimental results have been set on the same scale where top views have been reduced to assist with the interpretation.

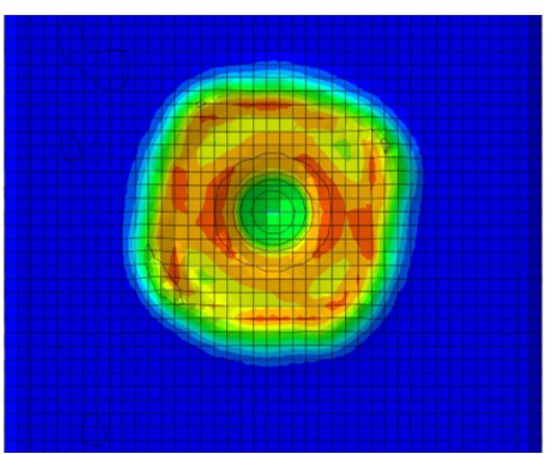

(a)

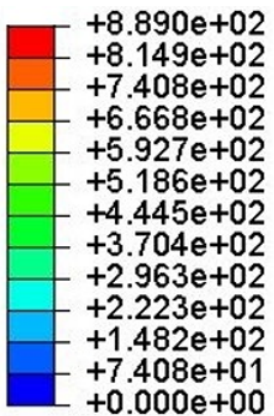

$+0.000 \mathrm{e}+00$

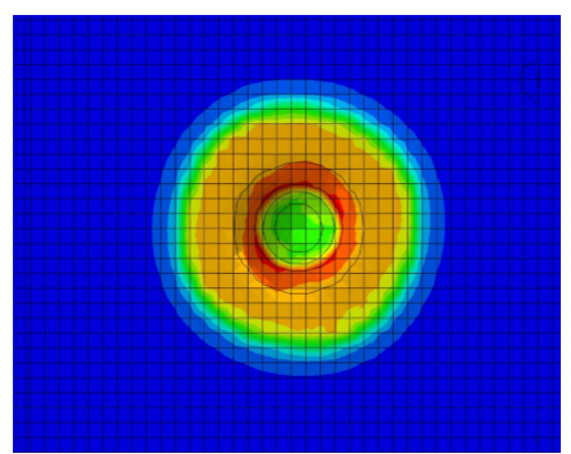

(b)

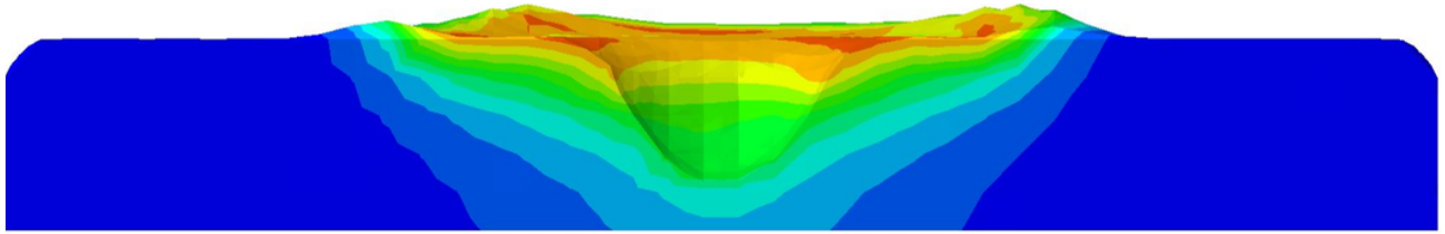

(c)

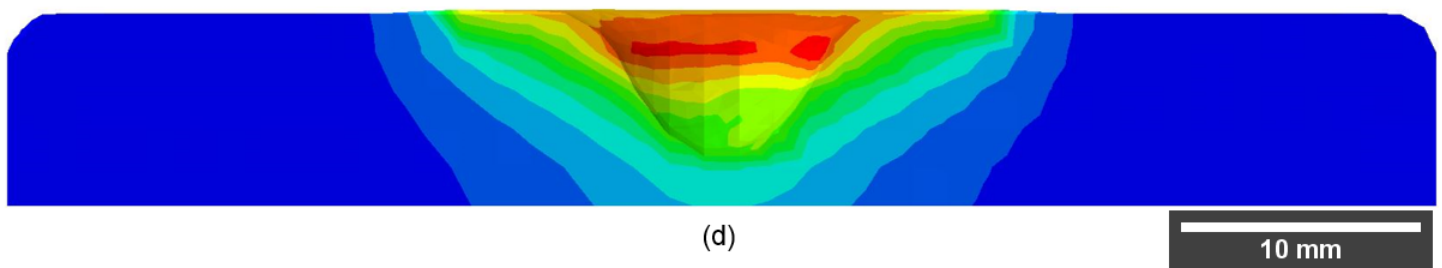

Fig. 6. Temperature distribution in ${ }^{\circ} \mathrm{C}$ at the plunge stage; (a) Top view of the slow weld model, (b) Top view of the fast weld model, (c) Cross sectional view of the slow weld model and (d) Cross sectional view of the fast weld model. (Counter clockwise tool rotation, advancing side on the left).

In welding, the thermal cycle and plastic deformation greatly influence the material's strength. As FSW results in a very high plastic deformation, the elastic strain can be considered as negligible relative to the plastic strain [7]. The plastic strain profile has been discussed in the present study to understand the deformation during all FSW stages 
by visualising top and cross sectional views of the weld. Fig. 7 exhibits the equivalent plastic strain distribution in top and cross sectional view of the slow and fast weld models for the plunge stage. Maximum plastic strain has been recorded in the slow weld model (Fig. 7a\&c). Whereas in the fast weld model (Fig. 7b\&d), increased rotational speed promoted the generation of a slip effect between the tool and workpiece that reduced the plastic strain as compared to that in the slow weld model. Thus, the slow weld model exhibits a larger plastic strain area than the fast weld model as seen in both top and cross sectional views (Fig. 7).

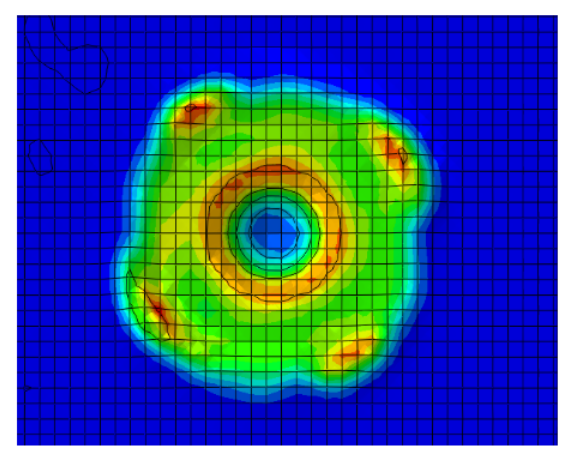

(a)

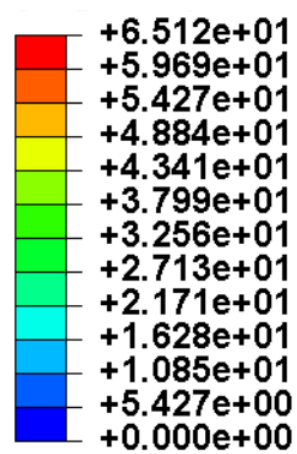

$+0.000 \mathrm{e}+00$

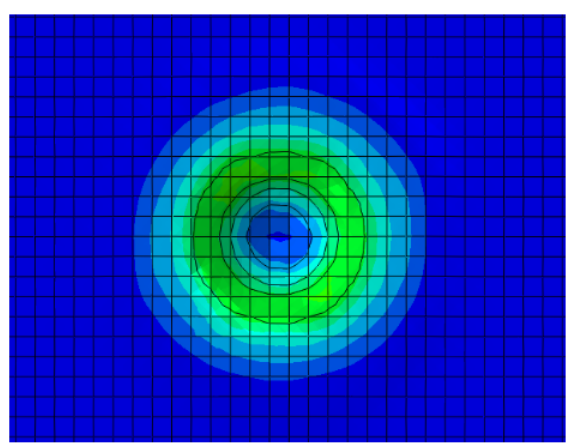

(b)

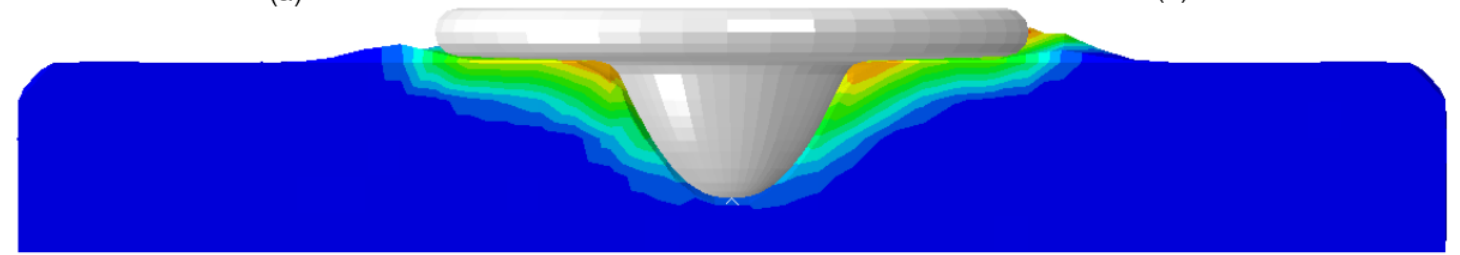

(c)

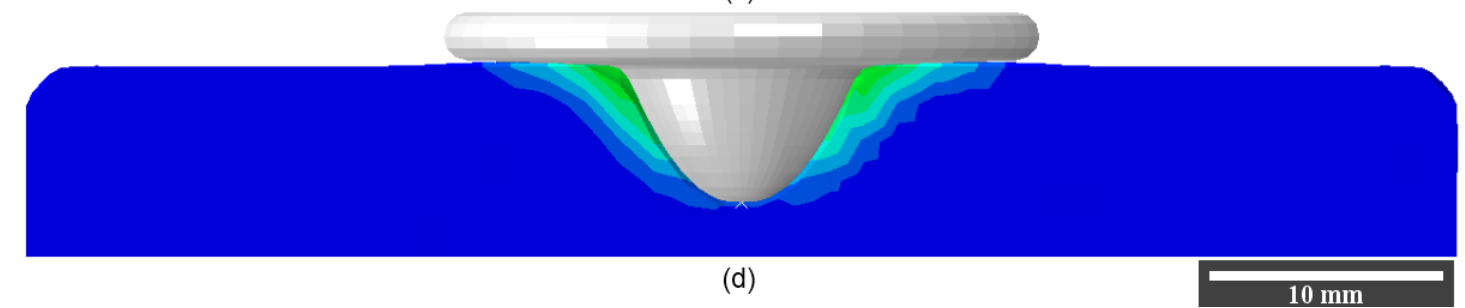

Fig. 7. Equivalent plastic distribution at the plunge stage; (a) Top view of the slow weld model, (b) Top view of the fast weld model, (c) Cross sectional view of the slow weld model and (d) Cross sectional view of the fast weld model. (Counter clockwise tool rotation, advancing side on the left).

\subsection{Dwell stage}

In dwelling, the temperature distribution in the slow weld model (Fig. 8a\&c) covers a larger area than the fast one (Fig. 8b\&d). As seen in Fig. 4, the conductivity of the material decreases with increasing temperature. This results in a reduction of the heat transfer in the workpiece. In contrast, temperature values are much higher in the fast 
weld model with a difference of $91{ }^{\circ} \mathrm{C}$. The maximum temperature in the slow weld model reached $993.7^{\circ} \mathrm{C}$ on the shoulder-workpiece interface, and in the fast weld model at $1084^{\circ} \mathrm{C}$ in the same region. The temperature profile tended to spread towards the sides and bottom. Since the tool had no translational movement, the temperature profile for both models was highly symmetrical with respect to the weld centreline. This demonstrates that the dwell time for the fast weld model can be reduced since it has more tendency to heat the surrounding material in less time. The non-uniformity in temperature distribution around the tool exhibited on the surface of both models is attributed to the flash generation during the process.

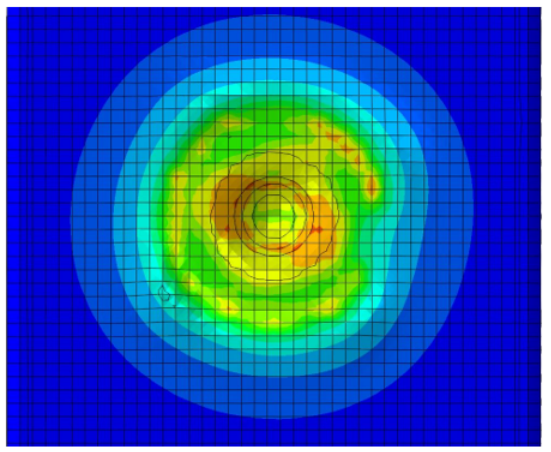

(a)

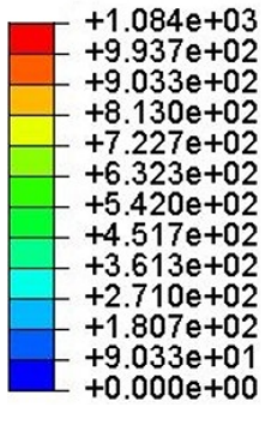

$0.000 \mathrm{e}+00$

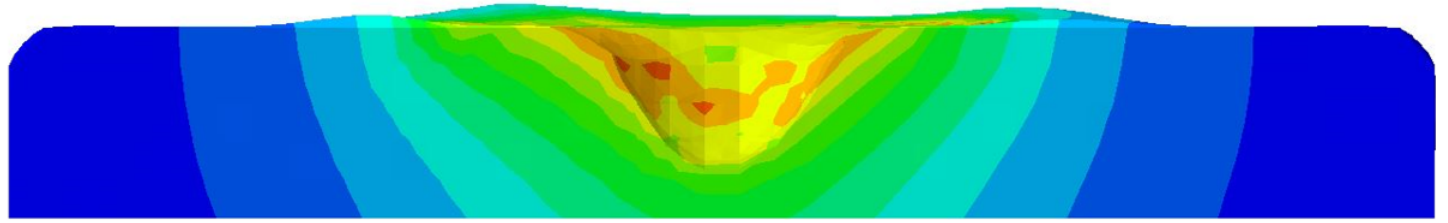

(c)

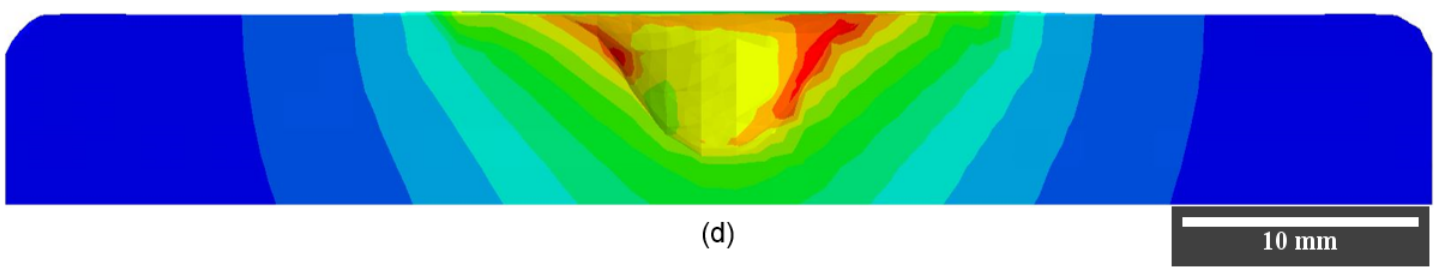

Fig. 8. Temperature distribution in ${ }^{\circ} \mathrm{C}$ at the dwell stage; (a) Isometric view of the slow weld model, (b) isometric view of the fast weld model, (c) cross sectional view of the slow weld model and (d) cross sectional view of the fast weld model. (Counter clockwise tool rotation, advancing side on the left).

As in the plunge stage, the plastic strain in the dwell stage is greater in the slow weld model (Fig. 9a\&c) compared to the fast weld (Fig. 9b\&d). A maximum strain of 64.22 is achieved on the surface of the slow weld model (Fig. 9a) due to the excessive flash generation. Both models tend to present symmetrical plastic strain distribution across the vertical axis of the tool. Reduced plastic strain is observed in the bottom tip of the 
tool probe in both models, which could result in potential defects due to incomplete stirring.

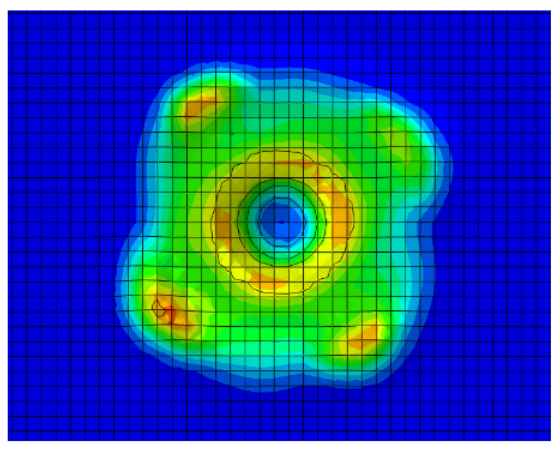

(a)

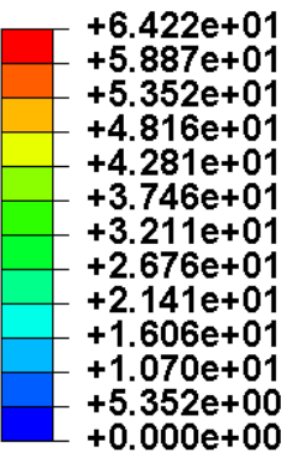

$+0.000 \mathrm{e}+00$

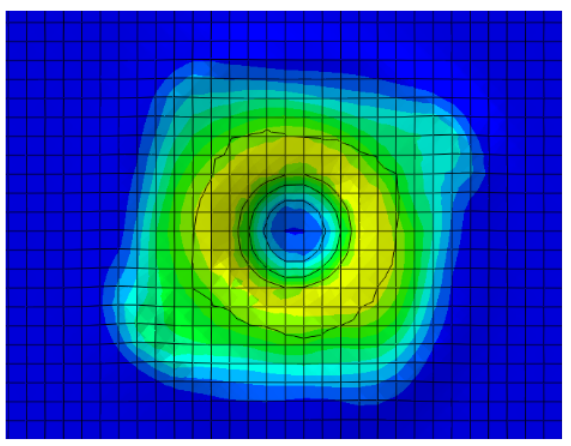

(b)

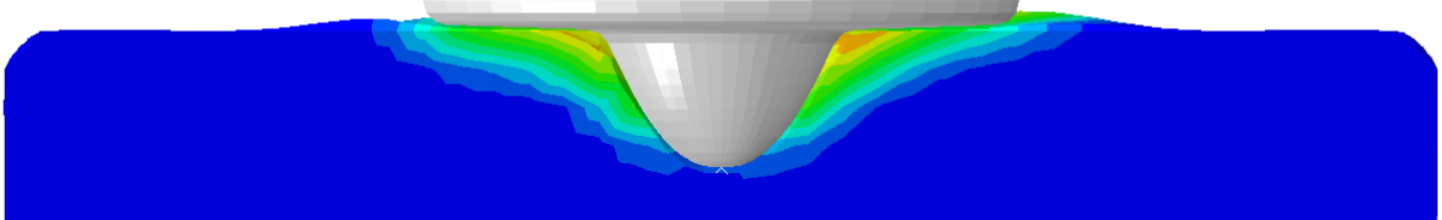

(c)

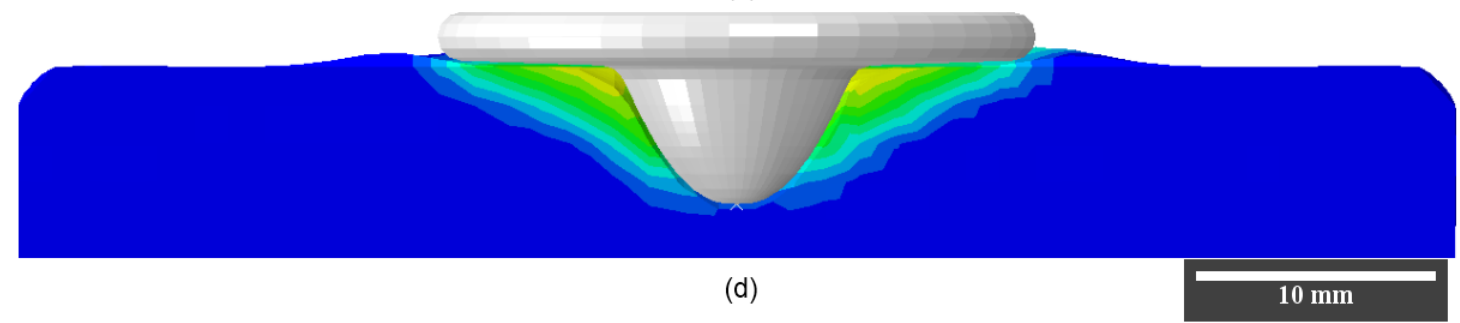

Fig. 9. Equivalent plastic distribution at the dwell stage; (a) Top view of the slow weld model, (b) Top view of the fast weld model, (c) Cross sectional view of the slow weld model and (d) Cross sectional view of the fast weld model. (Counter clockwise tool rotation, advancing side on the left).

\subsection{Traverse stage}

The numerical results produced for both models have been compared with the experimental work of prior publication [6] as shown in Fig. 10. The HAZ in the slow weld is much larger as compared to the corresponding region in the fast weld, since more heat per unit length was transferred to the workpiece by the slower movement of the tool. The maximum temperature reached in the slow weld model is $964^{\circ} \mathrm{C}$ and in the fast weld model is $1157^{\circ} \mathrm{C}$. The $\mathrm{HAZ}$ is in the range of $578^{\circ} \mathrm{C}$ to $771^{\circ} \mathrm{C}$ for the slow weld model and $674^{\circ} \mathrm{C}$ to $867^{\circ} \mathrm{C}$ for the fast weld model. Temperature values are higher in the advancing side than the retreating side for both models. The temperature profile 
on the workpiece's surface in the fast weld model is much narrower than the one in the slow weld model. The decreased traversing speed of the tool resulted in expanding the heat dissipation across the workpiece, whereas the fast traversing speed restricted the heat in the TMAZ, along with a narrow HAZ The fast weld model is creating the same asymmetry between advancing and retreating side as the realistic welding. This was reported by Micallef at el. [28] as well for the case of high speed welds. The fast weld parameters are potentially desirable with regard to increased productivity with acceptable quality welds on an industrial scale, while the slow weld parameters can be beneficial for producing excellent quality and symmetrical welds.

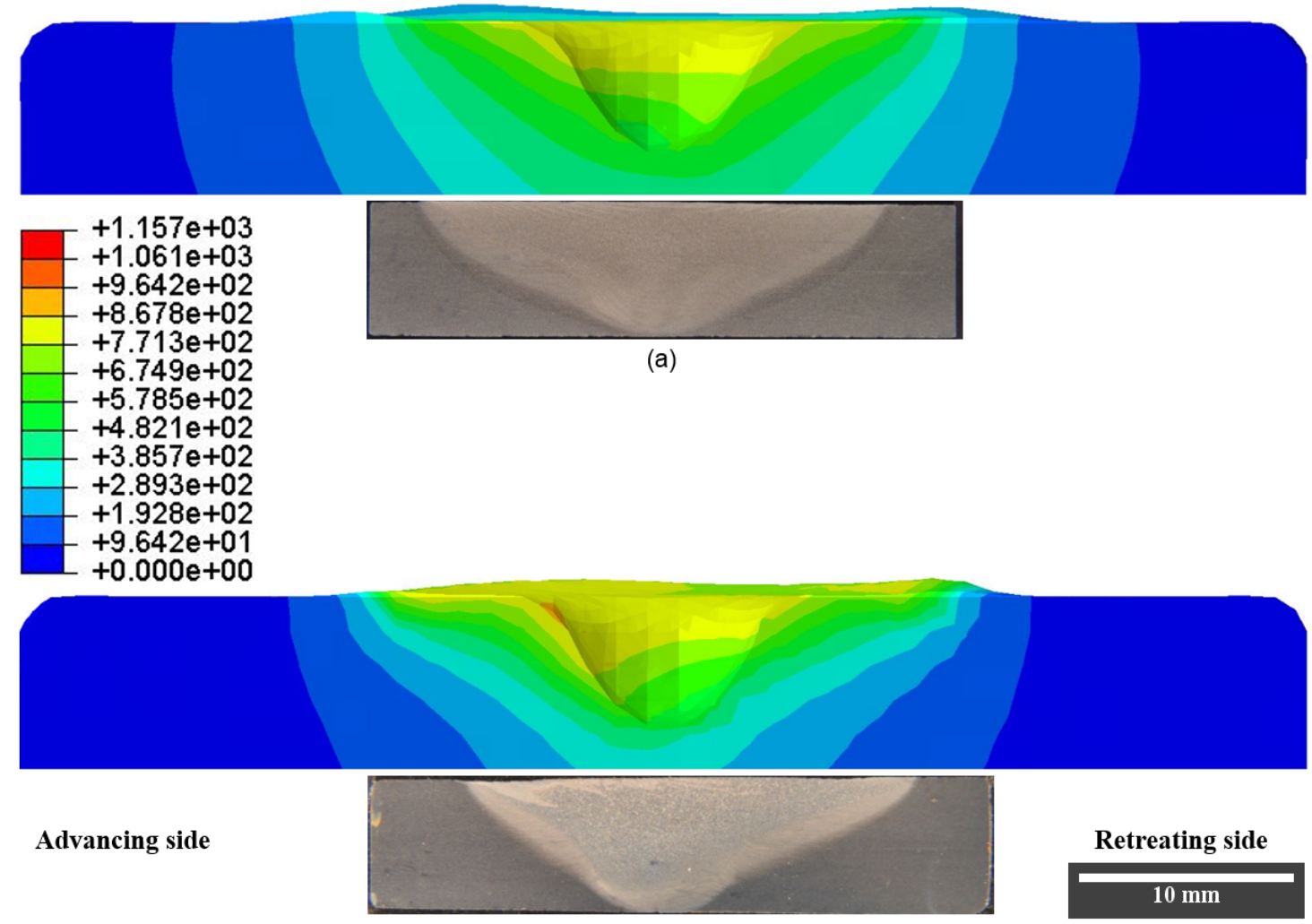

(b)

Fig. 10. Temperature distribution in ${ }^{\circ} \mathrm{C}$ at the traverse stage; Numerical and experimental cross sectional views of the (a) Slow weld model (b) Fast weld model. Macrographs from $[6]$.

To observe the thermal cycles during the FSW process, temperature change over time has been recorded for six nodal points in the workpiece. Three of them are located on the retreating side, and the rest are on the advancing side as shown in Fig. 11. The points recording the temperature are on a cross-sectional area at the distance of $13.5 \mathrm{~mm}$ from the tool's initial plunge position. 


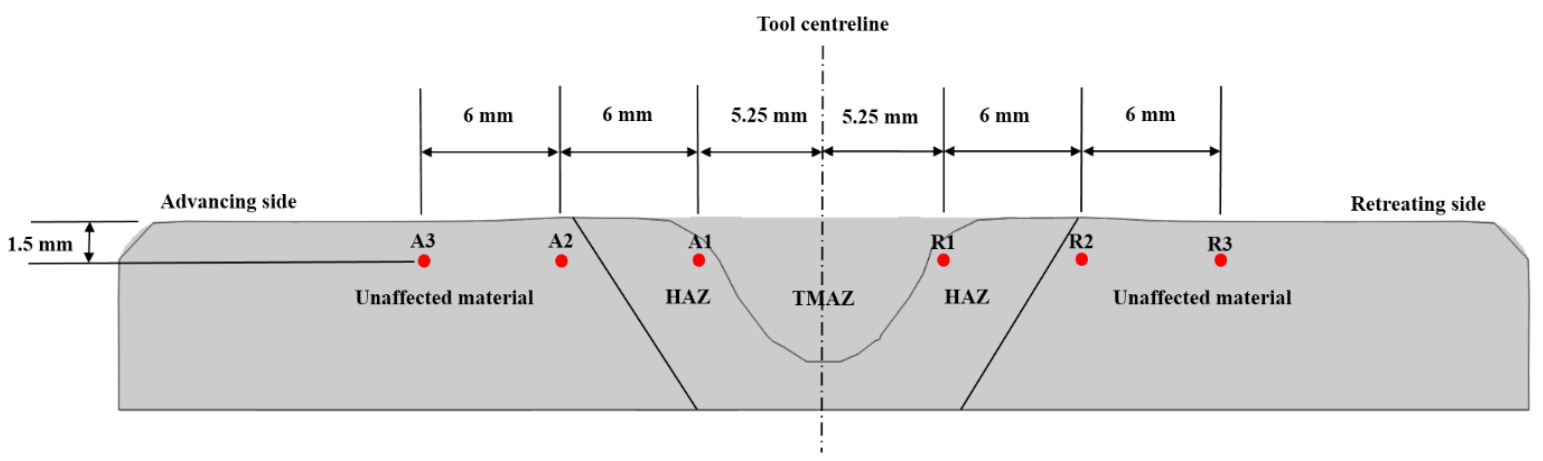

Fig. 11. Location of nodal points on the workpiece for monitoring temperature changes with respect to time.

The thermal cycles for the fast and slow weld models at specified nodal points are shown in Fig. 12 and Fig. 13, respectively. The nodal points A1 and R1 lie in the HAZ region whereas A2, A3, R2 and R3 lie in the unaffected region. The plunge, dwell and traverse stages start from $0,3.56$ and 7.56 seconds, respectively. It is observed that the temperature profiles over time of the nodes in the advancing side are higher than the respective nodes in the retreating side. In addition, a gradual decrease in the heating and cooling rates can be visualised from the nodes closer to the tool centreline than the ones far from it. A similar pattern of results has been reported by Nandan et al. [33].

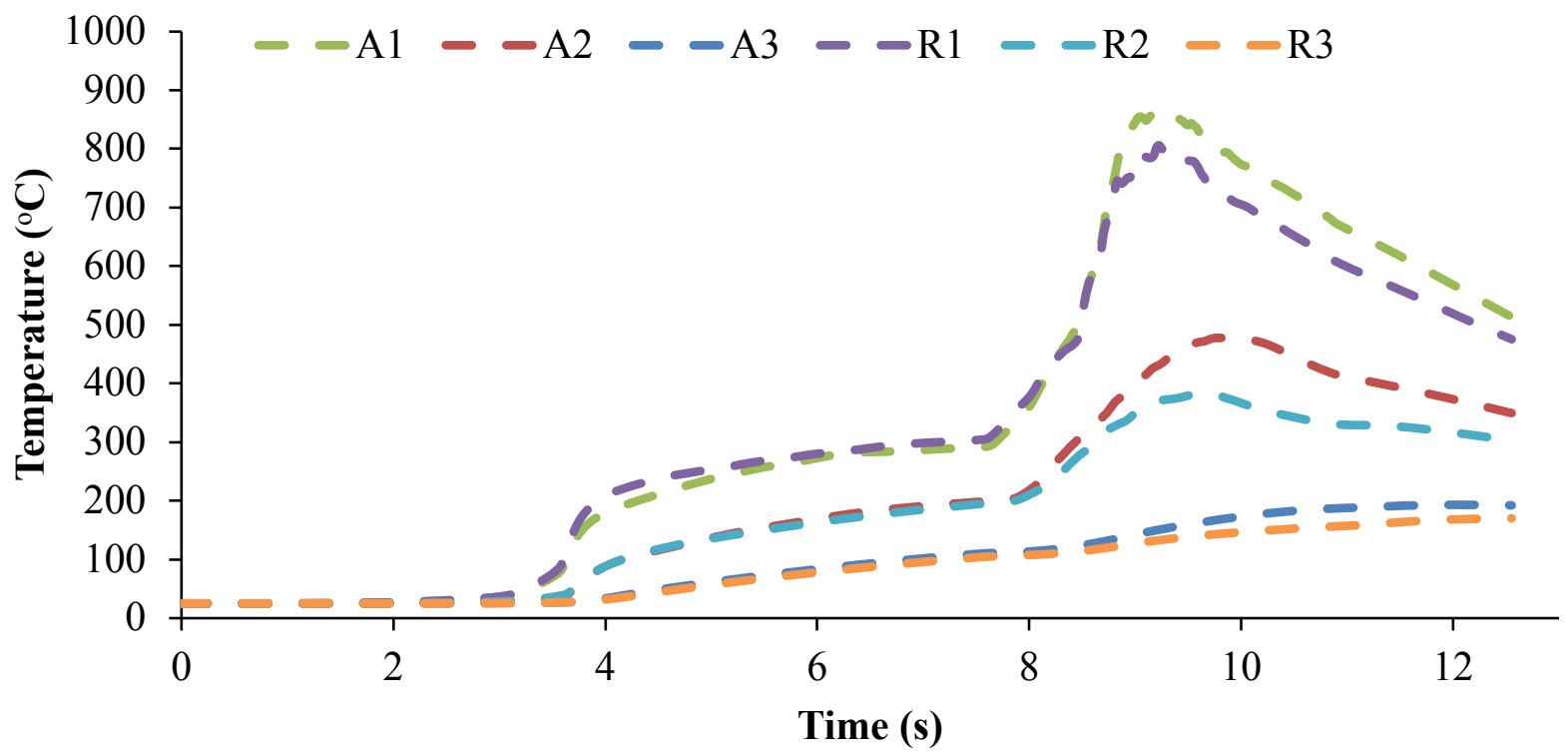

Fig. 12. Thermal cycle for the fast weld model.

In the slow weld model, the temperature profile for all respective nodes appears to follow same slopes during heating. Whereas during the cooling period, nodes on the retreating side tend to have slower rate than the ones on the advancing side. In CEL 
approach, the material moves independently to the mesh in the Eulerian region, and the temperature profile is recorded for the given nodal point irrespective of the material movement as shown in Fig. 11. Therefore, the perturbations in the temperature profiles can be related to the independent movement of flash material above the nodal points $\mathrm{A} 1, \mathrm{~A} 2, \mathrm{R} 1$ and $\mathrm{R} 2$.

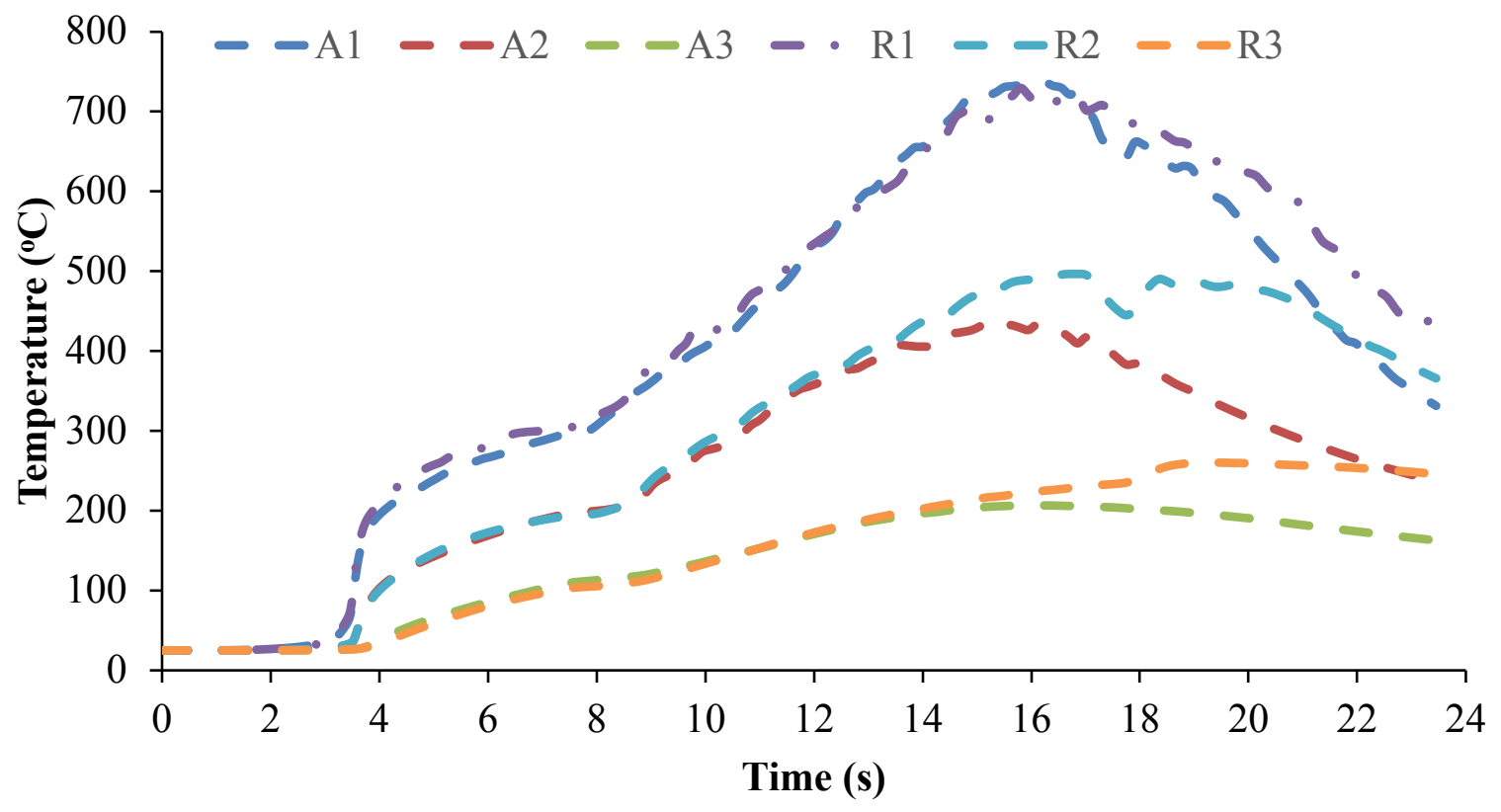

Fig. 13. Thermal cycle for the slow weld model.

It is shown in Fig. 14 that plastic strain distribution is not symmetric across the vertical axis for both models. The advancing side in both Fig. 14c\&d has a higher average plastic strain than the retreating side of each weld. The plastic strain region is extensive near the tool probe and shoulder interface. In comparison to the surface near to the shoulder, the area towards the tool probe experienced reduced plastic strain. 


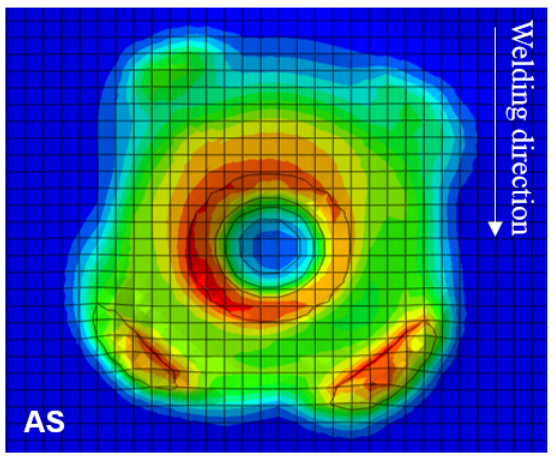

(a)

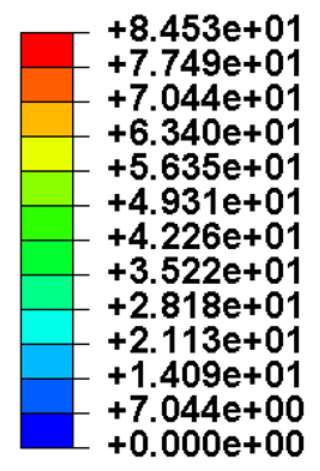

$+0.000 \mathrm{e}+00$

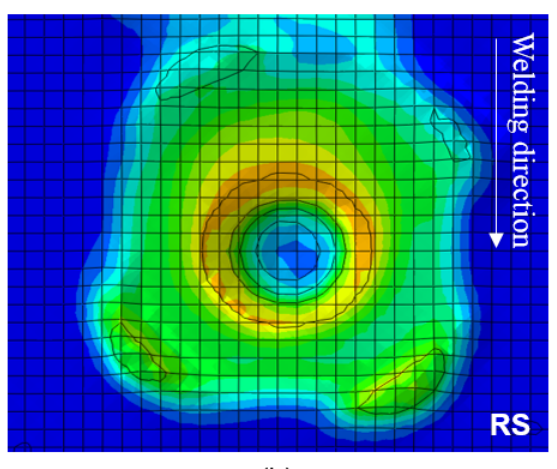

(b)

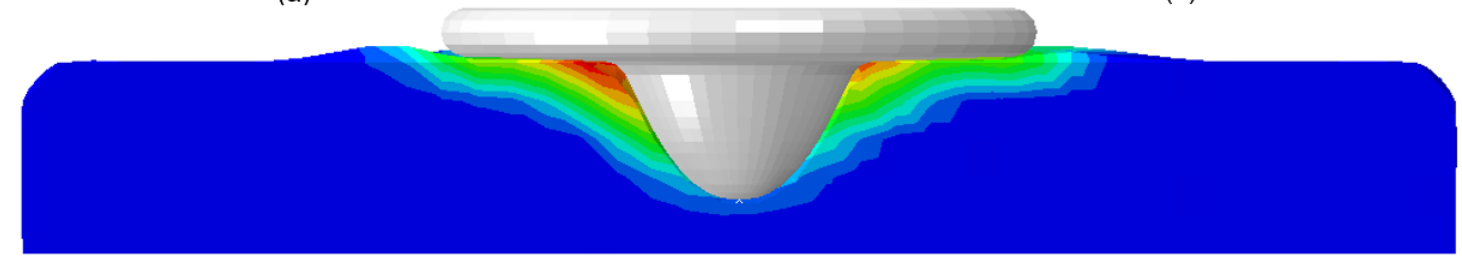

(c)

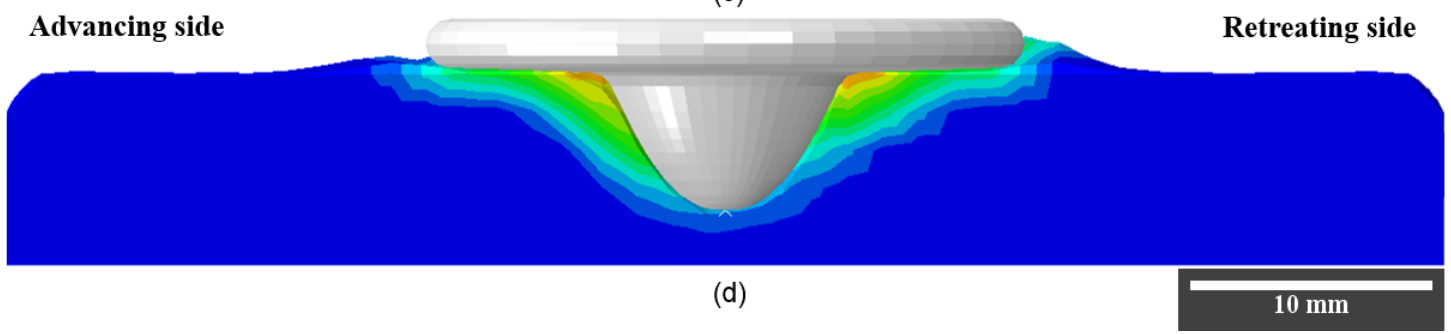

Fig. 14. Equivalent plastic strain distribution at the Traverse stage; (a) Top view of the slow weld model, (b) Top view of the fast weld model, (c) Cross sectional view of the slow weld model and (d) Cross sectional view of the fast weld model. (Counter clockwise tool rotation).

\subsection{Flash and potential defect generation}

Top surface and cross-sectional macrographs were produced for the actual FS welds and the numerical models. The maximum flash was observed on the workpiece's surface in the slow weld model only (Fig. 17a). This occurred since the slow traversing speed resulted in lower peak temperatures and the material on the upper surface of the workpiece was abraded away instead of thermos-mechanically stirred. 


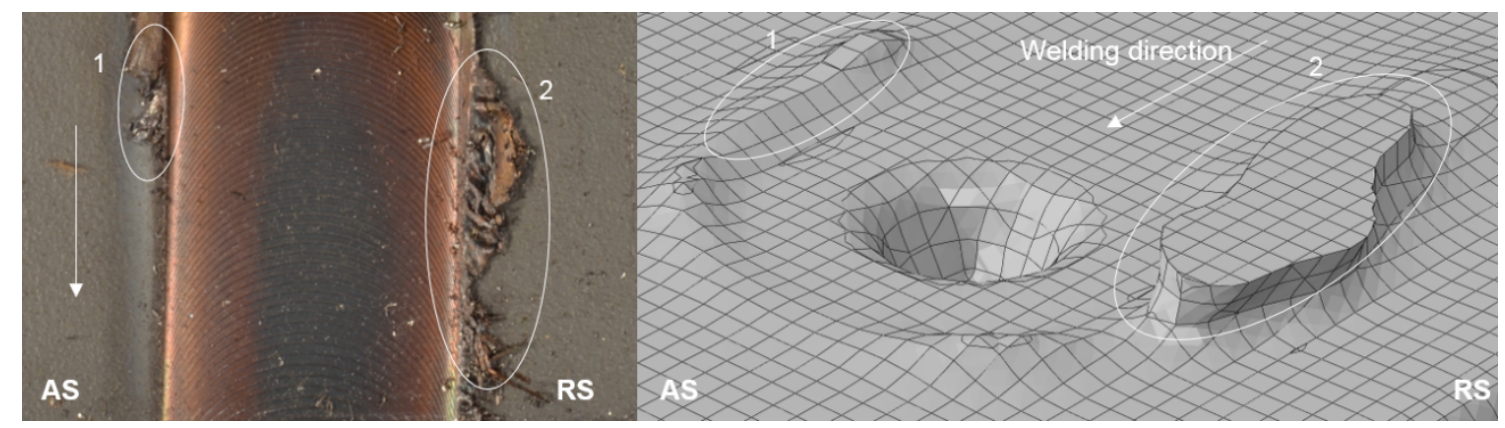

Fig. 15. Visualisation of flash generated experimentally and numerically in the slow weld model.

However, in the fast weld model, high rotation and translation of the tool led to maximum stirring in the TMAZ hence producing insignificant flash. Similar results have also been seen in weld macrographs for both of these models as shown in Fig. 15 and 16.

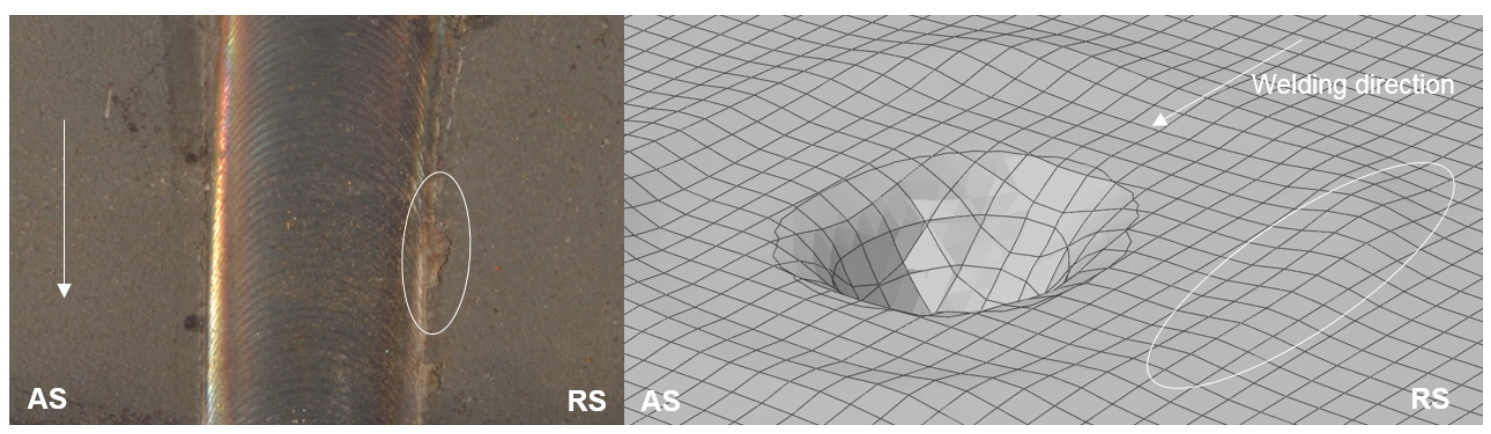

Fig. 16. Visualization of flash generated experimentally and numerically in the fast weld model.

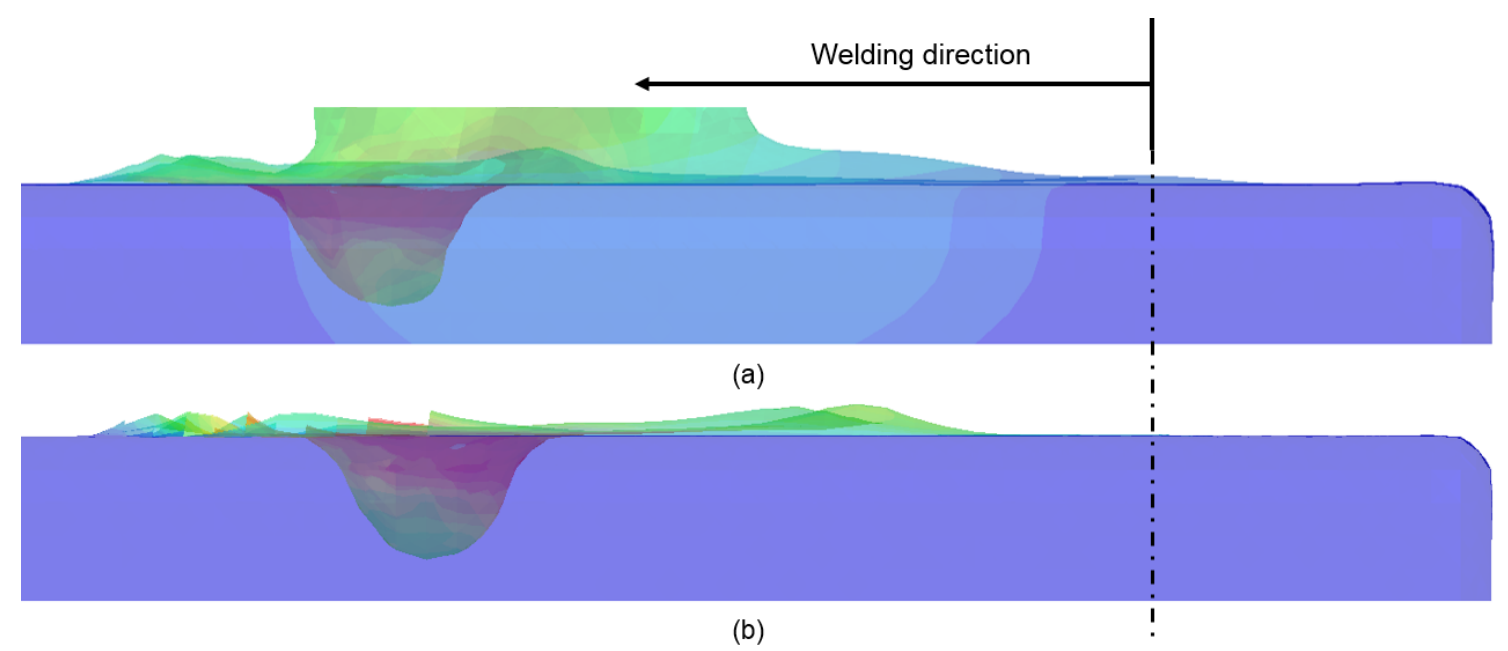

Fig. 17. Visualisation of flash and weld from the side view in the (a) slow weld model, (b) fast weld model. 
In FSW, even small changes in the process parameters can generate certain defects in the joints [8]. The application of different process parameters in FSW helps to overcome these possible defects. This also allows the researcher to analyse various other changes occurring due to them. Table 4 lists the key property differences between the two set of weld models.

Table 4. Major findings from the numerical results for both models.

\begin{tabular}{|c|c|c|}
\hline Weld model & Slow weld & Fast weld \\
\hline $\begin{array}{c}\text { Tool rotational speed } \\
\text { Traverse speed }\end{array}$ & $200 \mathrm{rpm}$ & $700 \mathrm{rpm}$ \\
\hline $\begin{array}{c}\text { Max. temperature } \\
\text { achieved at Plunge }\end{array}$ & $720 \mathrm{~mm} / \mathrm{min}$ & $889^{\circ} \mathrm{C}$ \\
\hline $\begin{array}{c}\text { Max. temperature } \\
\text { achieved at Dwell }\end{array}$ & $994^{\circ} \mathrm{C}$ & $1084^{\circ} \mathrm{C}$ \\
\hline $\begin{array}{c}\text { Max. temperature } \\
\text { achieved at Traverse }\end{array}$ & $964^{\circ} \mathrm{C}$ & $1157^{\circ} \mathrm{C}$ \\
\hline Flash formation & High & Low \\
\hline
\end{tabular}

\section{Conclusions}

A three-dimensional numerical model of friction stir welding for low alloy steel grade DH36 was developed in Abaqus/Explicit software. Since the Johnson Cook's model exhibits an unrealistic melting temperature for the case of steel alloys, real time temperature dependent material data have been used for the workpiece. By using the coupled Eulerian Lagrangian approach, both tool and workpiece were modelled as solid bodies and minimal assumptions were made for the boundary conditions. The model successfully predicted the temperature distribution, plastic strain and flash generation in all three stages, i.e. plunge, dwell and traverse in the workpiece. Use of experimentally generated temperature dependent $\mathrm{DH} 36$ properties provided an accurate behaviour of the complete welding process. Results of two characteristic models with substantially different rotational and traverse speeds were discussed. It was observed that the heataffected zone in the slow weld model was larger than the fast weld model in the traverse stage. This indicates that the fast weld parameters can be used where increased productivity with acceptable weld quality is desirable, and the slow weld parameters can 
be applied where excellent quality is preferred. Major flash was observed on the retreating side of the slow weld model workpiece whereas the weld upper surface in the fast weld model showed slight incomplete fusion. No flaws were detected in both models, which demonstrates that the process is durable for diverse process parameters. All the results obtained from the software were in good agreement with the experimental conclusions.

\section{Acknowledgements}

Results were obtained using the EPSRC funded ARCHIE-WeSt High Performance Computer (www.archie-west.ac.uk). EPSRC grant no. EP/K000586/1.

\section{References}

[1] Zhang YN, Cao X, Larose S, Wanjara P. Review of tools for friction stir welding and processing. Can Metall Q 2012;51:250-61. doi:10.1179/1879139512Y.0000000015.

[2] Shi L, Wu CS, Padhy GK, Gao S. Numerical simulation of ultrasonic field and its acoustoplastic influence on friction stir welding. Mater Des 2016;104:102-15. doi:10.1016/j.matdes.2016.05.001.

[3] Rai R, De A, Bhadeshia HKDH, DebRoy T. Review: friction stir welding tools. Sci Technol Weld Join 2011;16:325-42.

doi:10.1179/1362171811Y.0000000023.

[4] Salih OS, Ou H, Sun W, McCartney DG. A review of friction stir welding of aluminium matrix composites. Mater Des 2015;86:61-71. doi:10.1016/j.matdes.2015.07.071.

[5] Potluri H, Jones JJ, Mears L. Comparison of Electrically-Assisted and Conventional Friction Stir Welding Processes by Feed Force and Torque. ASME 2013 Int Manuf Sci Eng Conf 2013:V001T01A055. doi:10.1115/MSEC20131192.

[6] Toumpis A, Galloway A, Cater S, McPherson N. Development of a process envelope for friction stir welding of DH36 steel - A step change. Mater Des 2014;62:64-75. doi:10.1016/j.matdes.2014.04.066.

[7] Toumpis AI, Galloway AM, Arbaoui L, Poletz N. Thermomechanical deformation behaviour of DH36 steel during friction stir welding by 
experimental validation and modelling. Sci Technol Weld Join 2014;19:653-63. doi:10.1179/1362171814Y.0000000239.

[8] $\mathrm{He} \mathrm{X}, \mathrm{Gu} \mathrm{F}, \mathrm{Ball} \mathrm{A}$. A review of numerical analysis of friction stir welding. Prog Mater Sci 2014;65:1-66. doi:10.1016/j.pmatsci.2014.03.003.

[9] Stevenson R, Toumpis A, Galloway A. Defect tolerance of friction stir welds in DH36 steel. Mater Des 2015;87:701-11. doi:10.1016/j.matdes.2015.08.064.

[10] Çam G. Friction stir welded structural materials: beyond Al-alloys. Int Mater Rev 2011;56:1-48. doi:10.1179/095066010X12777205875750.

[11] Toumpis A, Galloway A, Cater S, Micallef D, Poletz N, Arbaoui L. Advances in friction stir welding of steel - project HILDA. Transp. Res. Arena, 2014.

[12] Toumpis A, Galloway A, Cater S, Molter L. A techno-economic evaluation of friction stir welding of DH36 steel. 10th Int. Symp. Frict. Stir Weld., vol. 44, 2014.

[13] Camilleri D, Micallef D, Arbaoui L, Toumpis A, Galloway A. Numerical Modelling Techniques Applicable for the Prediction of Residual Stresses and Distortion due to Mild Steel DH36 Friction Stir Welding. 4th Int. Conf. Frict. Stir Welding, FSWP2015, Spain: 2015, p. 1-5.

[14] Camilleri D, Micallef D, Mollicone P. Thermal stresses and distortion developed in mild steel DH36 friction stir-welded plates: An experimental and numerical assessment. J Therm Stress 2015;38:485-508. doi:10.1080/01495739.2015.1015856.

[15] Gould JE, Feng Z. Heat flow model for friction stir welding of aluminum alloys. J Mater Process Manuf Sci 1998;7:185-94. doi:10.1106/648R-2CNE-2PD045L6.

[16] Schmidt H, Hattel J, Wert J. An analytical model for the heat generation in friction stir welding. Model Simul Mater Sci Eng 2004;12:143-57. doi:10.1088/0965-0393/12/1/013.

[17] Colligan KJ. Material Flow Behavior during Friction Stir Welding of Aluminum. Weld Journal, 1999;78:229.

[18] Al-moussawi M, Smith AJ, Young A, Cater S, Faraji M. Modelling of friction stir welding of DH36 steel. Int J Adv Manuf Technol 2017;92:341-60. 
doi:10.1007/s00170-017-0147-y.

[19] Xu S, deng X, Reynolds AP, Seidel TU. Finite element simulation of material flow in friction stir welding. Sci Technol Weld Join 2001;6:191-3. doi:10.1179/136217101101538640.

[20] Seidel TU, Reynolds AP. Two-dimensional friction stir welding process model based on fluid mechanics. Sci Technol Weld Join 2003;8:175-83. doi:10.1179/136217103225010952.

[21] Schmidt HNB, Dickerson TL, Hattel JH. Material flow in butt friction stir welds in AA2024-T3. Acta Mater 2006;54:1199-209. doi:10.1016/j.actamat.2005.10.052.

[22] Hoyos E, López D, Alvarez H. A phenomenologically based material flow model for friction stir welding. Mater Des 2016;111:321-30. doi:10.1016/j.matdes.2016.09.009.

[23] Ducobu F, Rivière-Lorphèvre E, Filippi E. Application of the Coupled EulerianLagrangian (CEL) method to the modeling of orthogonal cutting. Eur J Mech A/Solids 2016;59:58-66. doi:10.1016/j.euromechsol.2016.03.008.

[24] Skrzat A. Application of coupled Eulerian-Lagrangian approach in metal forming simulations. Sci Lett Rzesz Univ Technol - Mech 2012;84:25-35. doi:10.7862/rm.2012.9.

[25] Al-Badour F, Merah N, Shuaib A, Bazoune A. Coupled Eulerian Lagrangian finite element modeling of friction stir welding processes. J Mater Process Technol 2013;213:1433-9. doi:10.1016/j.jmatprotec.2013.02.014.

[26] Zhu Z, Wang M, Zhang H, Zhang X, Yu T, Wu Z. A Finite Element Model to Simulate Defect Formation during Friction Stir Welding. Metals (Basel) 2017;7:256. doi:10.3390/met7070256.

[27] Yu M, Li WY, Li JL, Chao YJ. Modelling of entire friction stir welding process by explicit finite element method. Mater Sci Technol 2012;28:812-7. doi:10.1179/1743284711Y.0000000087.

[28] Micallef D, Camilleri D, Toumpis A, Galloway A, Arbaoui L. Local heat generation and material flow in friction stir welding of mild steel assemblies. Proc Inst Mech Eng Part L J Mater Des Appl 2015;230:586-602. 
doi:10.1177/1464420715583163.

[29] Simulia 6.14. Abaqus Documentation. 6.5.3 Fully Coupled Thermal Analysis 2014.

[30] Simulia 6.14. Abaqus Documentation. 6.3.3 Explicit Dynamic Analysis 2014.

[31] MegaStir. Friction Stir Welding of High Melting Temperature Materials. 2013.

[32] Simulia 6.14. Abaqus Documentation. 23.2.3 Rate-Dependent Yield 2014.

[33] Nandan R, Roy GG, Lienert TJ, DebRoy T. Numerical modelling of 3D plastic flow and heat transfer during friction stir welding of stainless steel. Sci Technol Weld Join 2006;11:526-37. doi:10.1179/174329306X107692.

[34] Ambroziak A, Winnicki M, Laska P, Lachowicz M, Zwierzchowski M, Lesniewski J. Examination of friction coefficient in friction welding process of tubular steel elements. Arch Metall Mater 2011;56:975-80. doi:10.2478/v10172011-0107-8.

[35] Simulia 6.14. Abaqus Documentation. 37.2.1 Thermal Contact Properties 2014.

\section{Fig. captions}

Fig. 1. Illustration of the CEL approach with material assignment.

Fig. 2. FSW tool geometrical dimensions $[6,31]$.

Fig. 3. Simplified tool and workpiece geometrical dimensions.

Fig. 4. Temperature dependent thermal conductivity and specific heat capacity of DH36 steel [28].

Fig. 5. True stress vs strain curve at $900^{\circ} \mathrm{C}$ [7].

Fig. 6. Temperature distribution in ${ }^{\circ} \mathrm{C}$ at the plunge stage; (a) Top view of the slow weld model, (b) Top view of the fast weld model, (c) Cross sectional view of the slow weld model and (d) Cross sectional view of the fast weld model. (Counter clockwise tool rotation, advancing side on the left).

Fig. 9. Equivalent plastic distribution at the plunge stage; (a) Top view of the slow weld model, (b) Top view of the fast weld model, (c) Cross sectional view of the slow weld model and (d) Cross sectional view of the fast weld model. (Counter clockwise tool rotation, advancing side on the left). 
Fig. 8. Temperature distribution in ${ }^{\circ} \mathrm{C}$ at the dwell stage; (a) Isometric view of the slow weld model, (b) isometric view of the fast weld model, (c) cross sectional view of the slow weld model and (d) cross sectional view of the fast weld model. (Counter clockwise tool rotation, advancing side on the left).

Fig. 9. Equivalent plastic distribution at the dwell stage; (a) Top view of the slow weld model, (b) Top view of the fast weld model, (c) Cross sectional view of the slow weld model and (d) Cross sectional view of the fast weld model. (Counter clockwise tool rotation, advancing side on the left).

Fig. 10. Temperature distribution in ${ }^{\circ} \mathrm{C}$ at the traverse stage; Numerical and experimental cross sectional views of the (a) Slow weld model (b) Fast weld model. Macrographs from [6].

Fig. 11. Location of nodal points on the workpiece for monitoring temperature changes with respect to time.

Fig. 12. Thermal cycle for the fast weld model.

Fig. 13. Thermal cycle for the slow weld model.

Fig. 14. Equivalent plastic strain distribution at the Traverse stage; (a) Top view of the slow weld model, (b) Top view of the fast weld model, (c) Cross sectional view of the slow weld model and (d) Cross sectional view of the fast weld model. (Counter clockwise tool rotation).

Fig. 15. Visualisation of flash generated experimentally and numerically in the slow weld model.

Fig. 16. Visualization of flash generated experimentally and numerically in the fast weld model.

Fig. 17. Visualisation of flash and weld from the side view in the (a) slow weld model, (b) fast weld model.

\section{Table captions}

Table 1. Percentage chemical composition of DH36 with respect to weight.

Table 2. Material properties of the pcBN tool.

Table 3. Process parameter specifications for models used in the study.

Table 4. Major findings from the numerical results for both models. 